\title{
Plumbagin, a Potent Naphthoquinone from Nepenthes Plants with Growth Inhibiting and Larvicidal Activities
}

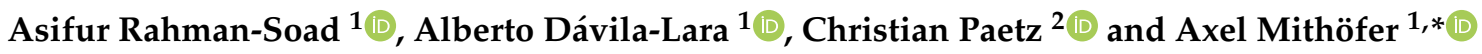 \\ 1 Research Group Plant Defense Physiology, Max Planck Institute for Chemical Ecology, 07745 Jena, Germany; \\ msoad@ice.mpg.de (A.R.-S.); adavila-lara@ice.mpg.de (A.D.-L.) \\ 2 Research Group Biosynthesis/NMR, Max Planck Institute for Chemical Ecology, 07745 Jena, Germany; \\ cpaetz@ice.mpg.de \\ * Correspondence: amithoefer@ice.mpg.de
}

check for updates

Citation: Rahman-Soad, A.;

Dávila-Lara, A.; Paetz, C.; Mithöfer,

A. Plumbagin, a Potent

Naphthoquinone from Nepenthes

Plants with Growth Inhibiting and

Larvicidal Activities. Molecules 2021,

26, 825. https://doi.org/10.3390/

molecules 26040825

Academic Editor: Giovanni Benelli

Received: 30 December 2020

Accepted: 1 February 2021

Published: 5 February 2021

Publisher's Note: MDPI stays neutral with regard to jurisdictional claims in published maps and institutional affiliations.

Copyright: (c) 2021 by the authors. Licensee MDPI, Basel, Switzerland. This article is an open access article distributed under the terms and conditions of the Creative Commons Attribution (CC BY) license (https:// creativecommons.org/licenses/by/ $4.0 /)$.

\begin{abstract}
Some plant species are less susceptible to herbivore infestation than others. The reason for this is often unknown in detail but is very likely due to an efficient composition of secondary plant metabolites. Strikingly, carnivorous plants of the genus Nepenthes show extremely less herbivory both in the field and in green house. In order to identify the basis for the efficient defense against herbivorous insects in Nepenthes, we performed bioassays using larvae of the generalist lepidopteran herbivore, Spodoptera littoralis. Larvae fed with different tissues from Nepenthes $x$ ventrata grew significantly less when feeding on a diet containing leaf tissue compared with pitcher-trap tissue. As dominating metabolite in Nepenthes tissues, we identified a naphthoquinone, plumbagin (5-hydroxy2-methyl-1,4-naphthoquinone). When plumbagin was added at different concentrations to the diet of $S$. littoralis larvae, an $\mathrm{EC}_{50}$ value for larval growth inhibition was determined with $226.5 \mu \mathrm{g} \mathrm{g}^{-1}$ diet. To further determine the concentration causing higher larval mortality, sweet potato leaf discs were covered with increasing plumbagin concentrations in no-choice-assays; a higher mortality of the larvae was found beyond $60 \mu \mathrm{g}$ plumbagin per leaf, corresponding to $750 \mu \mathrm{g} \mathrm{g}^{-1}$. Plantderived insecticides have long been proposed as alternatives for pest management; plumbagin and derivatives might be such promising environmentally friendly candidates.
\end{abstract}

Keywords: naphthoquinones; plumbagin; Spodoptera littoralis; insect growth inhibition; carnivorous plants; Nepenthes

\section{Introduction}

Nepenthes is a tropical plant genus occurring mainly in Southeast Asia. Plants of this genus are carnivorous. They attract, catch, and digest insect prey in order to get additional nutrients, primarily, nitrogen and phosphate [1,2]. Therefore, Nepenthes species developed a pitfall trap (Figure 1), called pitcher, where insect prey falls inside due to a slippery surface and drown in a digestive fluid [1,2]. As in many other carnivorous plants, also the genus Nepenthes harbors a large chemical diversity; currently, several secondary metabolites are isolated for pharmaceutical, biotechnological, and ethnobotanical use $[3,4]$. Especially, Nepenthes species are well known in traditional medicine. Multiple reports are in the literature describing curative effects of Nepenthes extracts on diseases, e.g., on hypertension, cough, fever, urinary system infections [5], malaria [6,7], pain, asthma [7], Staphylococcus infection [8], celiac disease [9], and oral cancer cells [10].

However, up to now, most of the chemical analysis in Nepenthes has been done for the digestive pitcher fluid. Here, metabolites with antimicrobial properties have been found, e.g., naphthoquinones (NQ; droserone, 5-O-methyl droserone in N. khasiana [11]; plumbagin, 7-methyl-juglone in N. ventricosa [12]). Thus, it is hypothesized that such compounds mediate protection against microbes and preserve prey during digestion [11-14]. NQ derivatives are also described for tissues of various Nepenthes species including the pitchers [12,15-17]. In particular, plumbagin is of broad pharmaceutical interest because 
it is a candidate that may be used in therapies against various cancers or chronic diseases [18-21]. In addition to NQ, carotenoids, flavonoids, sterols, and triterpenes are described for Nepenthes leaves $[1,22,23]$. Recently, an untargeted metabolomics approach was performed in N. $x$ ventrata comparing secondary metabolites of leaves and pitcher tissue before and after prey catches [24]. In that study, about 2000 compounds (MS/MS events) were detected in the two tissues showing enormous metabolome diversity, which was even higher in leaves. Strikingly, the tissue specificity of chemical compounds could significantly discriminate pitchers from leaves. Besides many yet unknown compounds, the common constituents were phenolics, flavonoids, and NQ [24]. These data suggest that the metabolite composition of the tissues can point to their function. In addition, the metabolite composition may represent mechanisms that promote the evolution of plant carnivory as well as enable the plants to cope with environmental challenges [14].

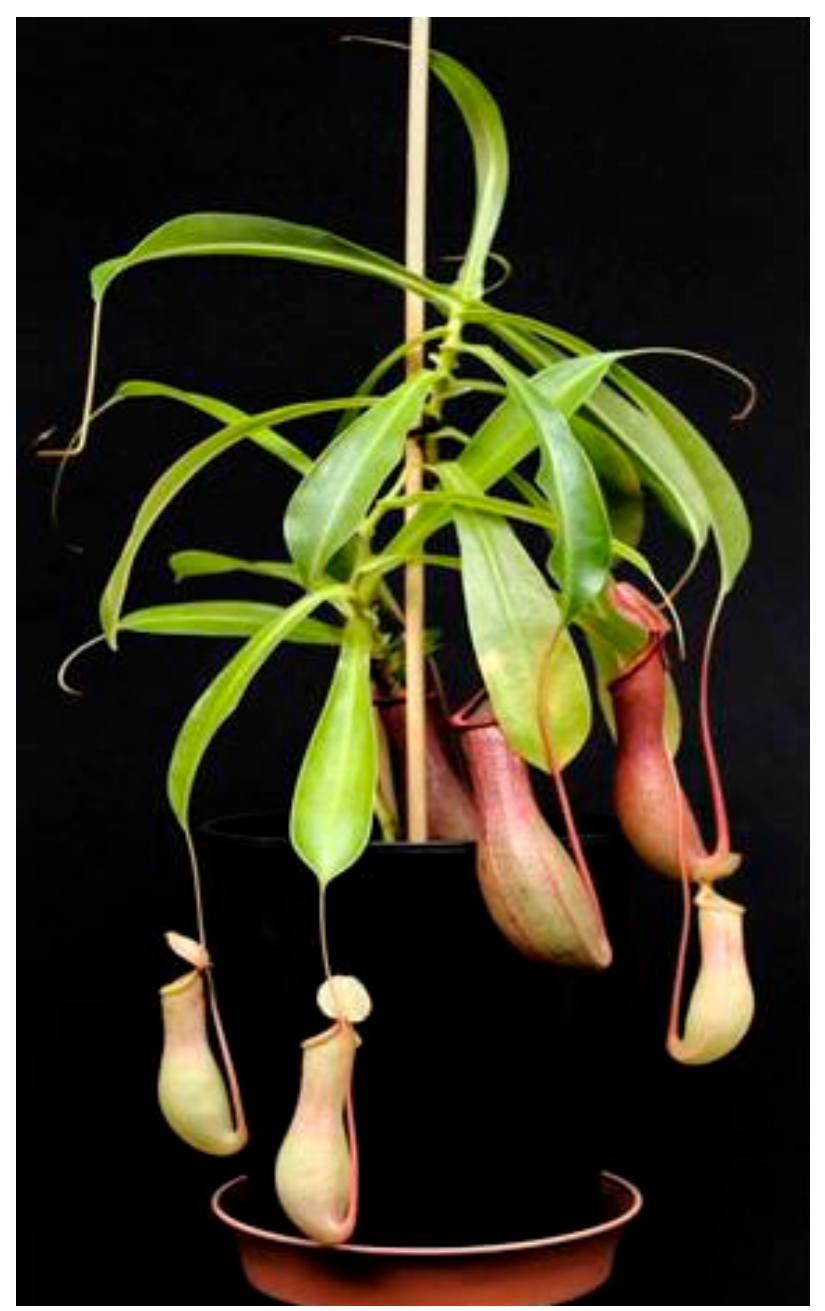

Figure 1. Nepenthes $x$ ventrata. A natural hybrid of N. ventricosa and N. alata. Copyright (C) A. Rahman-Soad.

(A)biotic challenges include the attack of herbivorous insects. Interestingly, there are only a very few observations and studies published concerning the attack of insects on tissues of carnivorous pitcher plants. Recently, lepidopteran herbivory was described for some species of the new world pitcher plant Sarracenia $[25,26]$. There is only one investigation showing that $N$. bicalcarata plants are attacked by an insect, the weevil Alcidodes spec. [27]. Another study shows that in N. gracilis red pitchers experience less herbivory than green ones [28]. To the best of our knowledge, no other studies have been published yet that focus on herbivore damage in Nepenthes. Obviously, the carnivorous syndrome obtained much more attention. However, herbivory on Nepenthes tissue is obviously rare. 
The reason for this is not known but it is unlikely that all herbivores are caught and digested. Instead, Nepenthes very likely has an efficient setting of defensive chemistry, which is not unusual in many plants [29]. In order to address this hypothesis and gain more insight in the ecological relevance of Nepenthes metabolites, we performed bioassays to study the effect of tissue of $N$. $x$ ventrata, a robust natural hybrid of $N$. alata and N. ventri$\cos a$, on the feeding behavior and larval development of the generalist insect herbivore Spodoptera littoralis.

\section{Results and Discussion}

\subsection{Effect of Nepenthes $x$ ventrata Tissue on Insect Larvae Growth}

The observation that Nepenthes plants are rarely infested by insect herbivores forced us to study this phenomenon. Therefore, freshly harvested tissues from N. $x$ ventrata leaves and pitchers were added to an artificial diet and fed to larvae of the generalist herbivore Spodoptera littoralis. As can be seen in Figure 2A, starting at day 4 to 5, the presence of leaf but not pitcher tissue significantly affected the performance of the larvae, which gained less weight. At this point, it might be worth to mention that recently in N. $x$ ventrata [24] and before in N. khasiana [15], the concentration of a NQ, very likely plumbagin, was determined to be significantly higher in leaves compared with pitchers, which may explain the result found in Figure 2A. We also could support these results by comparing plumbagin content in pitcher vs. leaf; by quantitative NMR analysis, we found a 5.2-fold higher plumbagin concentration in leaf compared with pitcher tissue (650 and $125 \mu^{-g ~ g ~}{ }^{-1} \mathrm{FW}$, respectively). Although significant, the growth inhibition effect was not very pronounced. Thus, the feeding experiment was repeated with dried leaf tissue in order to add more plant material to the diet, knowing that the water content of $N$. $x$ ventrata tissue is about $90 \%$ [24]. Here, the effect of the plant tissue was more distinct (Figure 2B). Both quantities of leaf tissue, $10 \%$ and $15 \%(w / w)$, showed clear impairment on the growth and weight of the feeding S. littoralis larvae already at day 2. Starting from day 3 on, there was also a significant difference between the larvae feeding on either $10 \%$ or $15 \%$ of Nepenthes tissue that was included in the diet (Figure 2B).

(A)

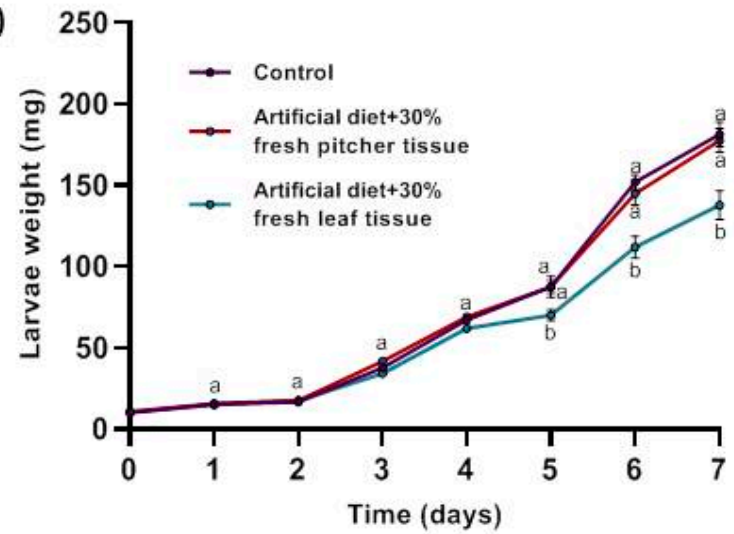

(B)

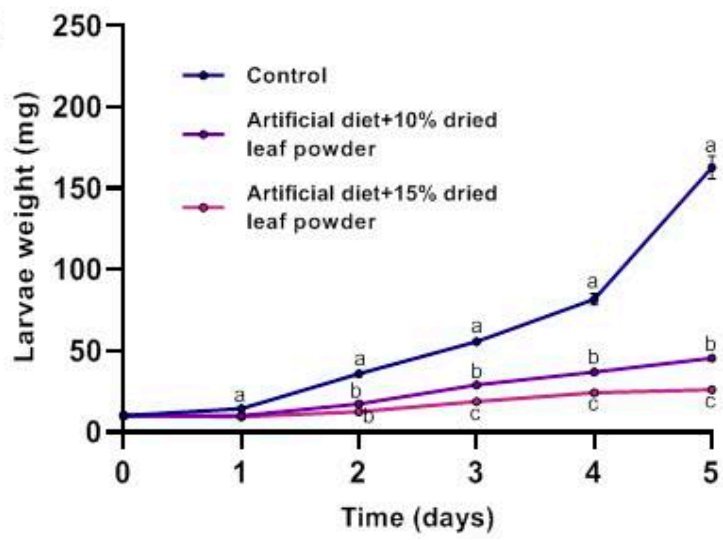

Figure 2. Performance of Spodoptera littoralis larvae feeding on artificial diet containing (A) fresh leaf powder of Nepenthes $x$ ventrata leaf and pitcher $(30 \%(w / w))$ or $(\mathbf{B})$ dried N. $x$ ventrata leaf powder $(10$ and $15 \%(w / w))$ Larvae were weighed every day for 7 days. Mean ( \pm SE) labelled with different letters indicate significant difference $(p<0.05)$; two-way ANOVA, Šidák's multiple comparisons test; $n=15$.

\subsection{Plumbagin in Nepenthes $x$ ventrata Tissue}

In many carnivorous plants belonging to the order Nepenthales [14], a sensu stricto sister group to Caryophyllales [30] and including the plant families Droseraceae and Nepenthaceae, the presence of NQ has been described [31]. This includes species such as Aldrovanda vesiculosus, Dionaea muscipula, Drosophyllum lusitanicum, as well as the genera Drosera and Nepenthes [31]. Among their secondary compounds, in particular, plumbagin 
is slightly volatile; thus, its presence in plant tissue is often indicated by spontaneous sublimation, thereby staining the tissue surface or plastic material used for storage. We observed this effect with both leaf and pitcher tissue (Figure 3) stored in plastic vials. In order to proof its identity, a part of the compound was removed from the wall of the plastic vial by extraction with dichloromethane.

(A)

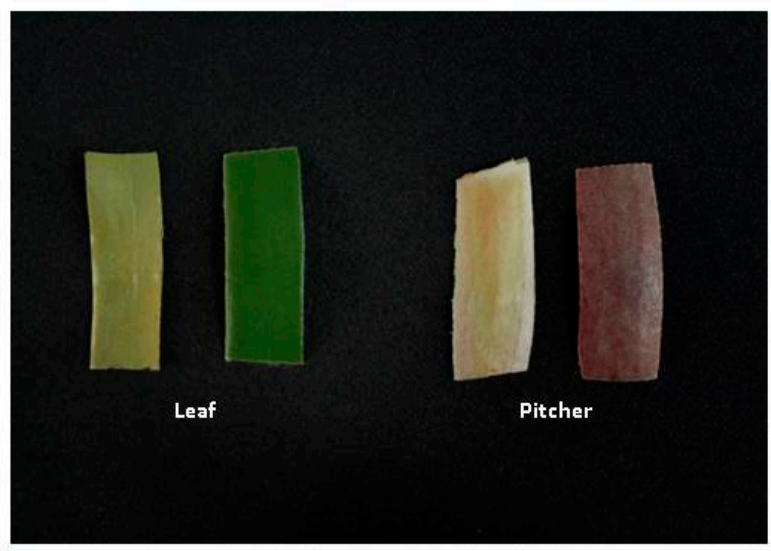

(B)

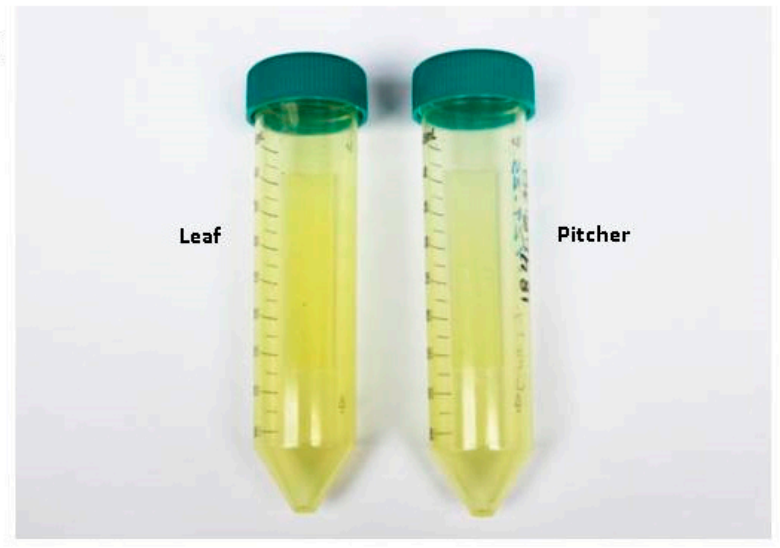

Figure 3. (A) Tissues of dry Nepenthes $x$ ventrata leaf and pitcher stored for 6 months in a plastic tube. Sublimed compounds cover the dry material with a yellowish color (left) in comparison with freshly cut tissue (right). (B) Plastic tubes that stored the different tissue types for 6 months. New tubes do not show any color.

After evaporation of the solvent, the residue was used for NMR analysis. In parallel, leaf extracts from N. $x$ ventrata were analyzed by ${ }^{1} \mathrm{H}-\mathrm{NMR}$ as well (Figure 4). When compared with a reference, it could be confirmed that the sublimed volatile compound was indeed plumbagin, and this compound could also be proven in leaf material (Figure 4).

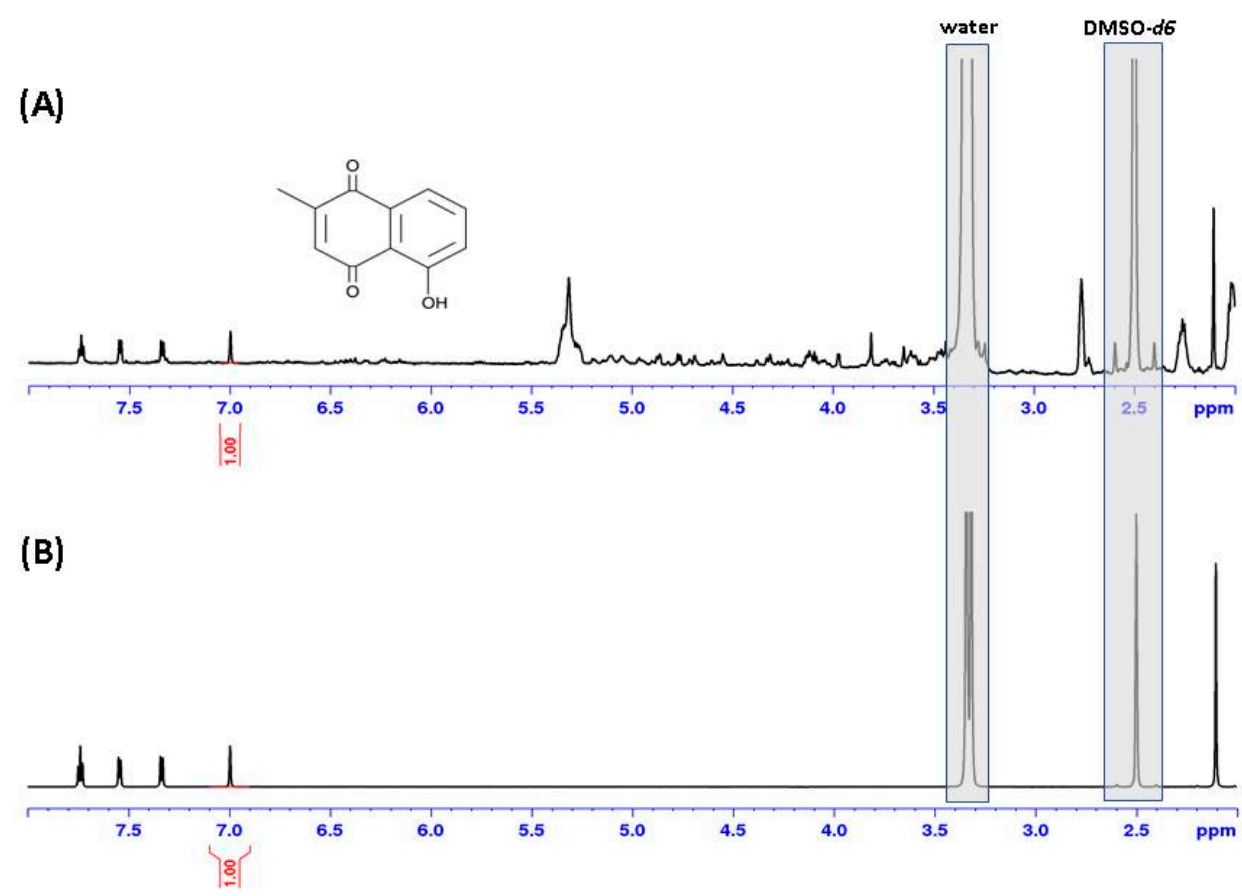

Figure 4. Cont. 


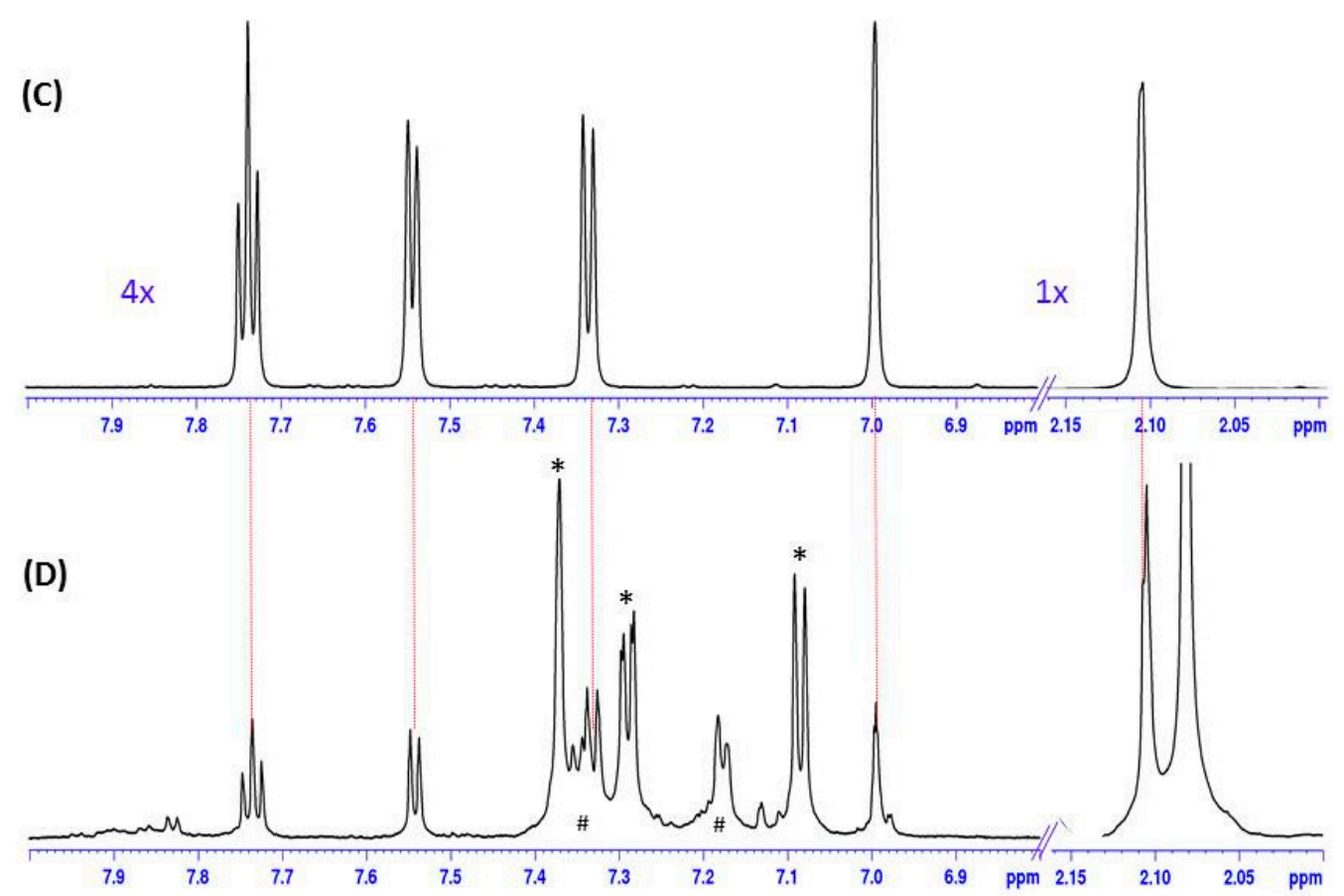

Figure 4. ${ }^{1} \mathrm{H}-\mathrm{NMR}$ spectra in DMSO- $d_{6}$. (A) Plumbagin (see insert) extracted from Nepenthes $x$ ventrata leaves and (B) a plumbagin reference. (C) Details of ${ }^{1} \mathrm{H}$ NMR spectra of a plumbagin reference and (D) the volatile exudate emitted by N. $x$ ventrata pitcher material. Asterisks $\left.{ }^{*}\right)$ indicate the presence of 4-tert-butylcatechol, a polymerization inhibitor probably extracted from the plastic material, and hashes (\#) account for an unidentified impurity. The intensity of the aromatic range in (C) was increased as indicated by the factor.

These results raised the question of the function of plumbagin and other NQ in carnivorous plants and in Nepenthes. In general, NQ are highly bioactive compounds. Besides pharmacological properties against malaria, various cancers, inflammation, and much more [6,19,32-34], they have allelopathic effects as shown for the walnut trees (Juglans spp.) releasing the phytotoxin juglone (5-hydroxy-1,4-naphthalenedione) [35,36]. Many defenserelated properties are associated with $\mathrm{NQ}$, among them are activities against numerous microbes including human- and phytopathogenic parasites, bacteria, and fungi [31-33]. That means, the NQ might protect the plants from pathogen infection. In addition, for $N$. khasiana, it could be shown that droserone and its derivative $5-O-$ droserone provided antimicrobial protection in the pitcher fluid of $[11,37]$. Buch and coworkers identified plumbagin and 7-methyl-juglone in the pitcher fluid of N. ventricosa [12]. These results suggest a role for $\mathrm{NQ}$ in the pitcher fluid in order to control the microbiome in the digestive fluid, together with, e.g., pathogenesis-related proteins such as PR-1 [13,37].

\subsection{Growth-Inhibiting and Larvicidal Activities of Plumbagin}

Besides the hypothesis that NQ are involved in defense against microbial infection, there are several studies showing that these compounds can also affect insects [31-33,38-43]. We, therefore, performed feeding experiments with plumbagin-supplemented artificial diet and measured the weight of $S$. littoralis larvae every day. Knowing that the amount of plumbagin in Nepenthes leaves is about $0.05 \%$ of fresh weight [15], we covered a concentra-

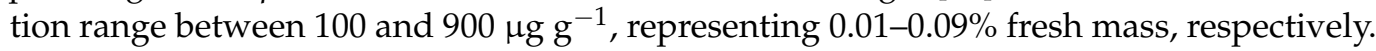
As shown in Figure 5, with increasing plumbagin concentrations, the larvae gained less weight. Based on these data the $\mathrm{EC}_{50}$ value was calculated indicating the plumbagin concentration necessary for $50 \%$ growth inhibition (weight gain), which was determined as $226.5 \mu \mathrm{g} \mathrm{g}^{-1}$ diet. For some lepidopteran species such as Spodoptera litura, Achaea janata, and Trichoplusia $n i$, it already has been shown that plumbagin affects the feeding behav- 
ior [38-41]. However, in those experiments, the focus of the analysis was on the level of feeding-avoidance rather than on the larval growth.

(A)

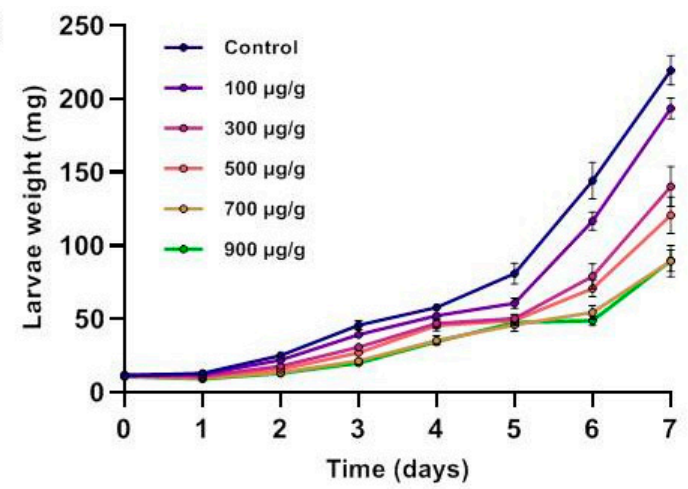

(B)

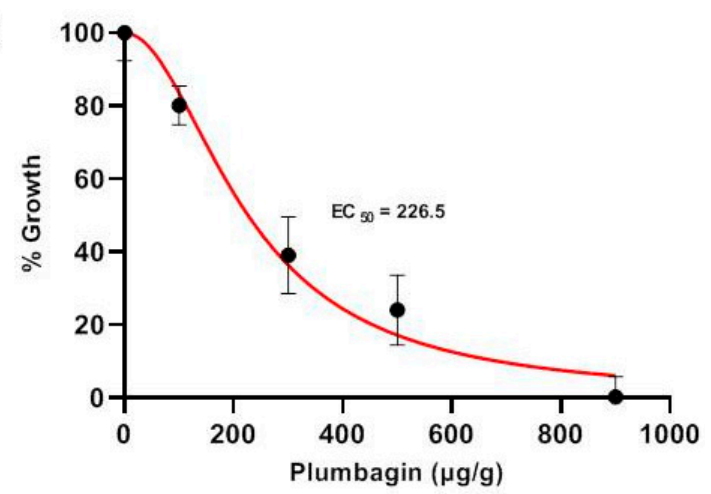

Figure 5. (A) Performance of Spodoptera littoralis larvae feeding on artificial diet containing various concentrations of plumbagin. Larvae were weighed every day for 7 days. Mean $( \pm \mathrm{SE}), n=15$. (B) Determination of $\mathrm{EC}_{50}$ value based on the data obtained in (A). $\mathrm{EC}_{50}$ was calculated with 226.5 and $1.2 \mu \mathrm{mol} \mathrm{g}^{-1}$ diet, respectively.

In contrast to most other bioassays that analyzed the antifeeding activity of plumbagin, here, the compound of interest was included in the food, not painted on leaves of various plant species. Nevertheless, in order to determine the mortality rate of larvae feeding on plumbagin, we also carried out an experiment using the approach with plumbagin-painted leaves. Therefore, a sweet potato cultivar (Tainong 66) that is known to be susceptible to herbivores and does not induce strong defense response upon attack was selected [44]. In first experiments, we observed that $S$. littoralis larvae even preferred cannibalism than feeding on those leaves. As a consequence, only individualized larvae were used. Up to a plumbagin concentration of $60 \mu^{-1}$ leaf $\left(13.3 \mu \mathrm{g} \mathrm{cm}^{-2}, 750 \mu \mathrm{g} \mathrm{g}^{-1}\right.$ leaf) no larvicidal effect was determined for the period analyzed (Figure 6A). With $90 \mathrm{\mu g}^{-1}$ leaf $\left(20 \mu \mathrm{g} \mathrm{cm}^{-2}\right.$; $1.125 \mathrm{mg} \mathrm{g}^{-1}$ leaf) dead larvae could be found at the end of day 4 and the survival rate drop to $50 \%$ at the end of day 5. At $120 \mu \mathrm{g}^{-1}$ leaf $\left(26.7 \mu \mathrm{g} \mathrm{cm}^{-2} ; 1.5 \mathrm{mg} \mathrm{g}^{-1}\right.$ leaf $)$, dead larvae were detected at day 3 and until the end of day 7, all larvae have died (Figure 6A). For $T$. $n i$ feeding on plumbagin-covered cabbage leaves, an antifeeding effect was also determined in the low microgram per square centimeter range [41]. It also can be seen that the larvae avoided feeding on the leaves covered with high concentrations of plumbagin (Figure 6B,C). With respect to the results shown in Figure 5, it seems that larval growth is heavily affected at higher plumbagin concentrations of around $700 \mu \mathrm{g}$ plumbagin $\mathrm{g}^{-1}$ diet. However, the larvae were affected in growth but still survived at all concentrations tested (up to $900 \mu \mathrm{g} \mathrm{g}^{-1}$ ). The plumbagin concentrations used in the no-choice assay also showed no mortality up to $750 \mu \mathrm{g} \mathrm{g}^{-1}$ leaf tissue. Only at the used concentration of $1.125 \mu \mathrm{g} \mathrm{g}^{-1}$ leaf, we found the first larvae dying. This suggests that there might be a threshold of about $1 \mathrm{mg} \mathrm{g}^{-1}$ food before the $S$. littoralis larvae begin to die. The experiment is somehow comparable with a recent study by Hu and colleagues [42]. They investigated the mortality of Pieris rapae and Helicoverpa armigera feeding on cabbage leaves dipped into solutions with different concentrations of plumbagin and juglone, respectively. For plumbagin, $\mathrm{IC}_{50}$ values of $11 \mu \mathrm{g} \mathrm{mL}{ }^{-1}$ (P. rapae) and $30 \mu \mathrm{g} \mathrm{mL}^{-1}$ (H. armigera) were calculated [42]. However, these data are hard to rank as it is not known how much of the compounds of interest was finally on or in the leaf disc. Nevertheless, for all the latter assays, it is difficult to discriminate whether the larvae really die either because of the ingested compounds or of hunger as they consequently avoid feeding. Other studies used topical assays where the compound was added directly onto the insect's (e.g., S. litura, A. janata, and Musa domestica) body to investigate the toxicity of compounds $[38,43]$. This approach is worth to carry out but not qualified for studies on activities of compounds that are incorporated during herbivory. 
(A)

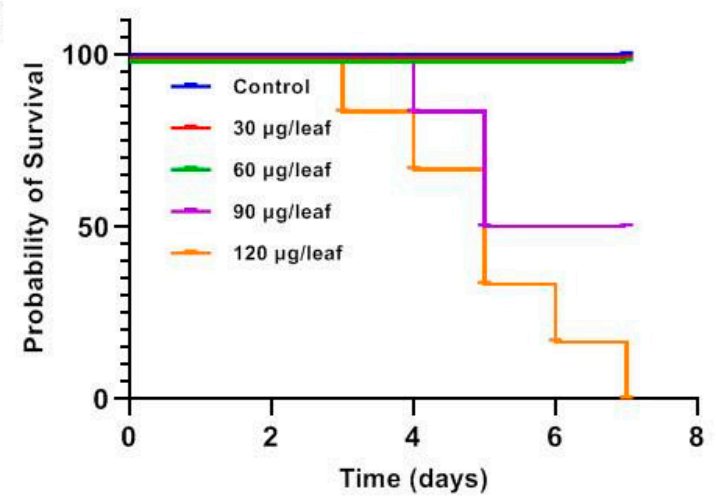

(B)
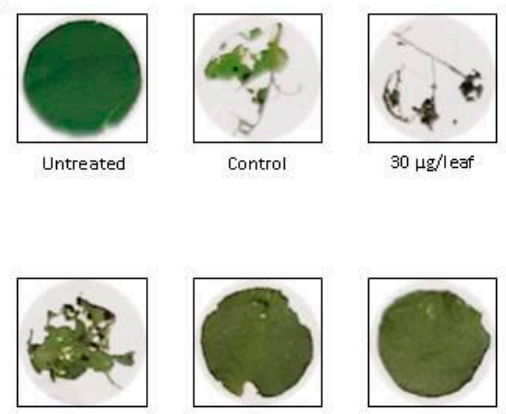

$60 \mu \mathrm{g} / \mathrm{leaf}$

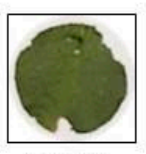

$90 \mu \mathrm{g} / \mathrm{leaf}$

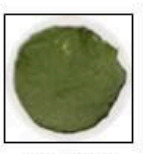

$120 \mu \mathrm{g} /$ leaf

(C)
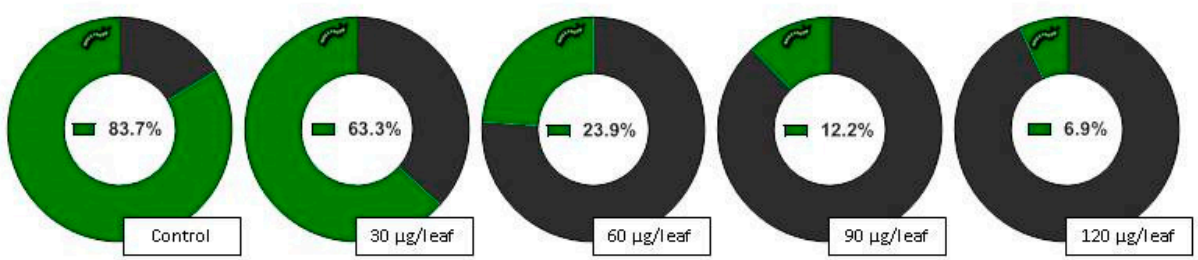

$\square$ Consumed leaf area

Remained leafarea

Figure 6. (A) Survival rate of Spodoptera littoralis larvae feeding on Ipomoea batatas (sweet potato) leaf discs painted with various concentrations of plumbagin $(n=6)$. (B) Representative leaf discs at the end of the feeding period of day three. Leaf disks were renewed every day. (C) Leaf areas consumed by $S$. littoralis larvae (indicated in green) at day 3 depending on the applied plumbagin concentration.

However, the mode of action of NQ is not completely known. In general, NQ are redoxactive compounds that can generate oxidative stress [33]; moreover, there are hints for specific inhibition of enzymes and, hence, processes involved in insect development mainly the molting process in insects, e.g., the enzymes phenoloxidase [30], chitin synthetase [45], or ecdysone 20-monooxygenase [46]. The interaction with molting hormone pools is discussed as well [47]. Another study showed that in Anopheles stephensi, the level of certain enzymes such as esterases and SOD was decreased significantly in the presence of plumbagin, which also was active as repellent against $A$. stephensi at a concentration of $100 \mu \mathrm{g} \mathrm{mL}-1$. Further histological investigations showed that muscles, midgut, and hindgut were the most affected tissues [48]. However, most studies suggest that, most likely, the insecticidal activity of plumbagin is based on the inhibition of ecdysis. This also includes a certain specificity against insects compared with neurotoxic insecticidal compounds.

Botanical or plant-derived insecticides have long been touted as environmentally friendly alternatives to synthetic insecticides for pest and disease management [3]; NQ combine the advantage of both low toxicity, compared with conventional pesticides, and restricted environmental contamination and, thus, might be promising candidates for an ecological agriculture.

\section{Materials and Methods}

\subsection{Insects and Plants}

Spodoptera littoralis Boisd. (Lepidoptera: Noctuidae) were hatched from eggs kindly provided by Syngenta Crop Protection (Stein, Switzerland) and reared on artificial diet (500 $\mathrm{g}$ hackled beans, $9 \mathrm{~g}$ ascorbic acid, $9 \mathrm{~g}$ 4-ethylbenzoic acid, $9 \mathrm{~g}$ vitamin E Mazola oil mixture (7.1\%), $4 \mathrm{~mL}$ formaldehyde, $1.2 \mathrm{~L}$ water, $1 \mathrm{~g}$-sitosterol, $1 \mathrm{~g}$ leucine, $10 \mathrm{~g}$ AIN76 vitamin mixture, and $200 \mathrm{~mL}(7.5 \%)$ agar-water solution) at $23-25{ }^{\circ} \mathrm{C}$ with a $14 \mathrm{~h}$ photoperiod. Sweet potato (Ipomoea batatas Lam. cv Tainong 66) scions were grown as described [40] under a $16 / 8 \mathrm{~h}$ light/dark regime at $28 / 25^{\circ} \mathrm{C}$, respectively, and $70 \%$ relative humidity. Nepenthes $x$ ventrata ( $N$. alata $x N$. ventricosa hybrid) plants were grown at $21-23{ }^{\circ} \mathrm{C}, 50-60 \%$ relative humidity, and a $16 / 8 \mathrm{~h}$ light/dark photoperiod. Pitcher and 
the associated leaf tissues were harvested at the time when the pitchers were just opened, directly frozen in liquid nitrogen and ground with mortar and pestle. Material was used directly (fresh) or freeze-dried before use.

\subsection{Feeding Assays}

For feeding assays, second to third instar larvae of $S$. littoralis were used. Ground fresh or dried plant material (leaves and pitcher) from $N$. $x$ ventrata was added to the artificial diet with the indicated quantities $(w / w)$. Plumbagin (5-hydroxy-2-methyl-1,4-naphthoquinone, $\mathrm{C}_{11} \mathrm{H}_{8} \mathrm{O}_{3}$; Fischer Scientific, Schwerte, Germany) was dissolved in acetone and added to the diet. Controls were prepared in the same way without plumbagin. At all the time, it was made sure that acetone was evaporated. For these feeding assays, 15 independent repeats were done. No-choice leaf disks feeding assays according to [34] were further performed on sweet potato. Therefore, leaf discs of $24 \mathrm{~mm}$ in diameter were punched out with a cork borer put directly on wet filter paper in a petri dish $(5.5 \mathrm{~cm}$ diameter). Plumbagin was solved as described before and diluted to the required concentration with 2.5\% $(w / v)$ PEG 2000 (Sigma-Aldrich, Taufkirchen, Germany). That solution was added onto the surface of the discs at the concentrations indicated. For the no-choice assays, 6 independent repeats were performed.

Every day fresh diet or leaf discs were provided. All assays were performed with individual larvae to avoid cannibalism. Larvae were reared for the indicated periods on the particular diets and weighed at the given time.

\subsection{Isolation of Plumbagin from Nepenthes $x$ ventrata Leaves}

Freshly harvested N. $x$ ventrata leaves $(7.3 \mathrm{~g})$ were immediately frozen in liquid $\mathrm{N}_{2}$ and freeze-dried. Dried tissue was ground and extracted with $100 \mathrm{~mL}$ dichloromethane (DCM) for $15 \mathrm{~min}$ by stirring in Erlenmeyer flasks. After precipitation for $20 \mathrm{~min}$, the clear supernatant $(50 \mathrm{~mL})$ was collected and another $50 \mathrm{~mL}$ DCM was added to the remaining material for re-extraction, which was repeated six times. Collected supernatants were filtered, combined, and DCM was removed using a rotary evaporator. The dried extract $(9.3 \mathrm{mg}$ ) was dissolved in $2 \mathrm{~mL}$ DCM transferred into a HPLC vial and dried again under $\mathrm{N}_{2}$ stream. For the whole procedure, only glassware was used. The NQ in the extract was identified by means of NMR spectroscopy by comparing spectral data with those of an authentic standard (plumbagin).

$N$. $x$ ventrata leaf material was kept in $50 \mathrm{~mL}$ polypropylene tubes at room temperature over 6 months during which the NQ sublimed (Figure 4), leaving a yellowish stained plastic material. Absorbed compounds were extracted from closed tubes with DCM $(10 \mathrm{~mL})$ for 3 days at room temperature. The extract was transferred into a glass vial and evaporated using $\mathrm{N}_{2}$ gas. The residue was reconstituted with DMSO- $d_{6}$ and subjected to NMR analysis.

Identity of the sublimed and extracted plumbagin was confirmed by ${ }^{1} \mathrm{H}-\mathrm{NMR}$ spectroscopy. NMR spectra were measured on a Bruker Avance III HD spectrometer (Bruker BioSpin GmbH, Rheinstetten, Germany) equipped with a cryoplatform and a TCI $1.7 \mathrm{~mm}$ Micro-CryoProbe. Spectra were referenced to the residual solvent signal for DMSO- $d_{6}$ at $\delta \mathrm{H}$ 2.50. Spectrometer control and data processing was accomplished using Bruker TopSpin 3.6.1, and standard pulse programs as implemented in Bruker TopSpin 3.6.1 were used.

For a quantitative comparison of ${ }^{1} \mathrm{H}$ NMR spectra of extracts of $N$. $x$ ventrata leaf and pitcher tissue, the spectral intensity was adjusted to equal solvent signal areas. The areas of signals accounting for plumbagin (range: $\delta \mathrm{H} \mathrm{8.00-7.00)} \mathrm{were} \mathrm{determined} \mathrm{and} \mathrm{used} \mathrm{for}$ calculation based on the respective areas of a plumbagin standard. For preparation of the experiment, $729 \mathrm{mg}$ (FW) of each tissue was ground in liquid $\mathrm{N}_{2}$ and extracted with $20 \mathrm{~mL}$ of dichloromethane in closed vessels at room temperature with shaking. Extracts were filtered through Chromabond PTS phase separation cartridges (Macherey-Nagel, Düren, Germany) and the flow-through was evaporated with $\mathrm{N}_{2}$ gas at room temperature within $30 \mathrm{~min}$. Afterwards, the residue was reconstituted with $1.2 \mathrm{~mL}$ DMSO- $d 6$ and subjected to ${ }^{1} \mathrm{H}-\mathrm{NMR}$ spectroscopy. 


\subsection{Statistical Analysis}

Statistical calculations were performed using GraphPad Prism version 9.0.0 in all cases. Details are indicated in the particular figure legends. For $\mathrm{EC}_{50}$ analysis, the total response was normalized to run between $0 \%$ and $100 \%$ using control data. For growth experiments, larvae were picked randomly from a large population and all experiments were conducted out under highly standardized conditions to avoid investigator-included bias.

\section{Conclusions}

Naphthoquinones are known metabolites in several plant species. Among these are various carnivorous plants including the pitcher plant Nepenthes. Plumbagin is a prominent $\mathrm{NQ}$ in Nepenthes $x$ ventrata and it was detected by ${ }^{1} \mathrm{H}-\mathrm{NMR}$ in tissues in different concentrations (100 and $650 \mathrm{\mu g} \mathrm{g}^{-1}$ fresh weight in pitcher and leaf, respectively). Plumbagin has known antimicrobial activities and is of pharmaceutical interest. Now, in different feeding assays with Spodoptera littoralis larvae the anti-feeding, growth-inhibiting and larvicidal activity of plumbagin or plumbagin-containing tissues was demonstrated at naturally occurring concentrations. Plumbagin as well as other NQ might become alternative compounds as natural insecticides in agriculture.

Author Contributions: A.R.-S., A.D.-L., and A.M. conceived the study and experiments. A.R.-S., A.D.-L., and C.P. performed the experiments and analyzed data. A.R.-S., A.D.-L., C.P., and A.M. discussed the data and wrote the manuscript. All authors have read and agreed to the published version of the manuscript.

Funding: A.D.-L. was supported by a PhD fellowship from the DAAD (German Academic Exchange Service).

Institutional Review Board Statement: Not applicable.

Informed Consent Statement: Not applicable.

Data Availability Statement: All data generated or analyzed during this study are included in the main text.

Acknowledgments: We thank the greenhouse team of the MPI for cultivating the plants, Syngenta for providing Spodoptera littoralis and Andrea Lehr for rearing larvae.

Conflicts of Interest: The authors declare no conflict of interest.

\section{References}

1. Juniper, B.E.; Robins, R.J.; Joel, D.M. The Carnivorous Plants; Academic Press: London, UK, 1989.

2. Thorogood, C.J.; Bauer, U.; Hiscock, S.J. Convergent and divergent evolution in carnivorous pitcher plant traps. New Phytol. 2018, 217, 1035-1041. [CrossRef]

3. Miguel, S.; Hehn, A.; Bourgaud, F. Nepenthes: State of the art of an inspiring plant for biotechnologists. J. Biotechnol. 2018, 265, 109-115. [CrossRef] [PubMed]

4. Legendre, G.; Darnowski, D.W. Biotechnology with carnivorous plants. In Carnivorous Plants: Physiology, Ecology, and Evolution; Ellison, A.M., Adamec, L., Eds.; Oxford University Press: Oxford, UK, 2018; pp. 270-282.

5. Chi, V.V. Dictionary of Vietnamese Medicinal Plants; Publishing House Medicine: Hanoi, Vietnam, $2012 ;$ Volume 2.

6. Likhitwitayawuid, K.; Kaewamatawong, R.; Ruangrungsi, N.; Krungkrai, J. Antimalarial naphthoquinones from Nepenthes thorelii. Planta Med. 1998, 64, 237-241. [CrossRef] [PubMed]

7. D'Amoto, P. The Savage Garden; Ten Speed Press: Berkeley, CA, USA, 1998.

8. Wiard, C.; Morgana, S.; Khalifah, S.; Mahan, M.; Ismael, S.; Buckle, M.; Narayana, A.K.; Sulaiman, M. Antimicrobial screening of plants used for traditional medicine in the state of Perak, Peninsula Malaysia. Fitoterapia 2004, 75, 68-73.

9. Rey, M.; Yang, M.; Lee, L.; Zhang, Y.; Sheff, J.G.; Sensen, C.W.; Mrazek, H.; Halada, P.; Man, P.; McCarville, J.L.; et al. Addressing proteolytic efficiency in enzymatic degradation therapy for celiac disease. Sci. Rep. 2016, 6, 30980. [CrossRef] [PubMed]

10. Tang, J.-Y.; Peng, S.-Y.; Cheng, Y.-B.; Wang, C.-L.; Farooqi, A.A.; Yu, T.-J.; Hou, M.-F.; Wang, S.-C.; Yem, C.-H.; Chan, L.-P.; et al. Ethyl acetat extract of Nepenthes adrianii $x$ clipeata induces antiproliferation, apoptosis, and DNA damage against oral cancer cells through oxidative stress. Environ. Toxcol. 2019, 34, 891-901. [CrossRef]

11. Eilenberg, H.; Pnini-Cohen, S.; Rahamim, Y.; Sionov, E.; Segal, E.; Carmeli, S.; Zilberstein, A. Induced production of antifungal naphthoquinones in the pitchers of the carnivorous plant Nepenthes khasiana. J. Exp. Bot. 2010, 61, 911-922. [CrossRef] 
12. Buch, F.; Rott, M.; Rottloff, S.; Paetz, C.; Hilke, I.; Raessler, M.; Mithöfer, A. 2013. Secreted pitfall-trap fluid of carnivorous Nepenthes plants is unsuitable for microbial growth. Ann. Bot. 2013, 111, 375-383. [CrossRef]

13. Mithöfer, A. Carnivorous pitcher plants: Insights in an old topic. Phytochemistry 2011, 72, 1678-1682. [CrossRef]

14. Hatcher, C.R.; Ryves, D.B.; Millett, J. The function of secondary metabolites in plant carnivory. Ann. Bot. 2020, 125, 399-411. [CrossRef]

15. Raj, G.; Kurup, R.; Hussain, A.A.; Baby, S. Distribution of naphthoquinones, plumbagin, droserone, and 5-O-methyl droserone in chitin-induced and uninduced Nepenthes khasiana: Molecular events in prey capture. J. Exp. Bot. 2011, 62, 5429-5436. [CrossRef]

16. Rischer, H.; Hamm, A.; Bringmann, G. Nepenthes insignis uses a C2-portion of the carbon skeleton of L-alanine acquired via its carnivorous organs, to build up the allelochemical plumbagin. Phytochemistry 2002, 59, 603-609. [CrossRef]

17. Schlauer, J.; Nerz, J.; Rischer, H. Carnivorous plant chemistry. Acta Bot. Gall. 2005, 152, 187-195. [CrossRef]

18. Liu, Y.; Cai, Y.; He, C.; Chen, M.; Li, H. Anticancer properties and pharmaceutical applications of plumbagin: A review. Am. J. Chin. Med. 2017, 45, 423-441. [CrossRef] [PubMed]

19. Tripathi, S.K.; Panda, M.; Biswal, B.K. Emerging role of plumbagin: Cytotoxic potential and pharmaceutical relevance towards cancer therapy. Food Chem. Toxicol. 2019, 215, 566-583. [CrossRef]

20. Yin, Z.H.; Zhang, J.J.; Chen, L.; Gio, Q.F.; Yang, B.C.; Zhang, W.; Kang, W.Y. Anticancer effects and mechanisms of action of plumbagin: Review of research advances. Biomed Res. Int. 2020. [CrossRef] [PubMed]

21. Panichayupakaranant, P.; Ahmad, M.I. Plumbagin and its role in chronic diseases. Adv. Exp. Med. Biol. 2016, 929, $229-246$.

22. Aung, H.; Chia, L.; Goh, N.K.; Chia, T.F.; Ahmad, A.A.; Pare, P.W.; Mabry, T.J. Phenolic constituents from the leaves of the carnivorous Nepenthes gracilis. Fitoterapia 2002, 73, 445-447. [CrossRef]

23. Wan, A.S.; Aexel, R.T.; Ramsey, R.B.; Nicholas, H.J. Sterols and triterpenes of the pitcher plant. Phytochemistry 1972, 11, $456-461$. [CrossRef]

24. Dávila-Lara, A.; Rodríguez-López, C.E.; O’Connor, S.E.; Mithöfer, A. Metabolomics analysis reveals tissue-specific metabolite compositions in leaf blade and traps of carnivorous Nepenthes plants. Int. J. Mol. Sci. 2020, 21, 4376. [CrossRef]

25. Carmickle, R.N.; Horner, J.D. Impact of the specialist herbivore Exyra semicrocea on the carnivorous plant Sarracenia alata: A field experiment testing the effects of tissue loss and diminished prey capture on plant growth. Plant Ecol. 2019, $220,553-561$. [CrossRef]

26. Lamb, T.; Kalies, E.L. An overview of lepidopteran herbivory on North American pitcher plants (Sarracenia), with a novel observation of feeding on Sarracenia flava. J. Lepid. Soc. 2020, 74, 193-197.

27. Merbach, M.A.; Zizka, G.; Fiala, B.; Merbach, D.; Booth, W.E.; Maschwitz, U. Why a carnivorous plant cooperates with an ant-selective defense against pitcher-nutritional mutualism in a pitcher plant destroying weevils in the myrmecophytic pitcher plant Nepenthes bicalcarata Hook. F. Ecotropica 2007, 13, 45-56.

28. Gilbert, K.J.; Nitta, J.H.; Talavera, G.; Pierce, N.E. Keeping an eye on coloration: Ecological correlates of the evolution of pitcher traits in the genus Nepenthes (Caryophyllales). Biol. J. Linn. Soc. 2018, 123, 321-337. [CrossRef]

29. Mithöfer, A.; Boland, W. Plant defense against herbivores: Chemical aspects. Annu. Rev. Plant Biol. 2012, 63, 431-450. [CrossRef] [PubMed]

30. Fleischmann, A.; Schlauer, J.; Smith, S.A.; Givnish, T.J. Evolution of carnivory in angiosperms. In Carnivorous Plants: Physiology, Ecology, and Evolution; Ellison, A.M., Adamec, L., Eds.; Oxford University Press: Oxford, UK, 2018; pp. $22-42$.

31. Devi, S.P.; Kumaria, S.; Rao, S.R.; Tandon, P. Carnivorous plants as a source of potent bioactive compounds: Naphthoquinones. Tropical Plant Biol. 2016, 9, 267-279. [CrossRef]

32. Bubla, P.; Adam, V.; Havel, L.; Kizek, R. Noteworthy secondary metabolites naphthoquinones-their occurrence, pharmacological properties and analysis. Curr. Pharm. Anal. 2009, 5, 47-68. [CrossRef]

33. Widhalm, J.R.; Rhodes, D. Biosynthesis and molecular actions of specialized 1,4-naphthoquinone natural products produced by horticultural plants. Hortic. Res. 2016, 3, 16046. [CrossRef]

34. Tripathi, K.S.; Rengasamy, K.R.R.; Biswal, B.K. Plumbagin engenders apoptosis in lung cancer celles via caspase-9 activation and targeting mitochondrial-mediated ROD induction. Arch. Pharm. Res. 2020, 43, 242-256. [CrossRef]

35. Soderquist, C.J. Juglone and allelopathy. J. Chem. Educ. 1973, 50, 782-783. [CrossRef]

36. Willis, R.J. Juglans spp., juglone and allelopathy. Allelopath. J. 2000, 7, 1-55.

37. Buch, F.; Pauchet, Y.; Rott, M.; Mithöfer, A. Characterization and heterologous expression of a novel PR-1 protein from traps of the carnivorous plant Nepenthes mirabilis. Phytochemistry 2014, 100, 43-50. [CrossRef] [PubMed]

38. Sreelatha, T.; Hymavathi, A.; Babu, K.S.; Murthy, J.M.; Pathipati, U.R.; Rao, J.M. Synthesis and insect antifeedant activity of plumbagin derivatives with the amino acid moiety. Agric. Food Chem. 2009, 57, 6090-6094. [CrossRef] [PubMed]

39. Tokunaga, T.; Takada, N.; Ueda, M. Mechanism of antifeedant activity of plumbagin, a compound concerning the chemical defense in carnivorous plant. Tetrahedron Lett. 2004, 45, 7115-7119. [CrossRef]

40. Tokunaga, T.; Dohmura, A.; Takada, N.; Ueda, M. Cytotoxic antifeedant from Dionaea muscipula Ellis: A defensive mechanism of carnivorous plants against predators. Bull. Chem. Soc. Jpn. 2004, 77, 537-541. [CrossRef]

41. Akhtar, Y.; Isman, M.B.; Niehaus, L.A.; Lee, C.-H.; Lee, H.-S. Antifeedant and toxic effects of naturally occurring and synthetic quinones to the cabbage looper, Trichoplusia ni. Crop Prot. 2012, 31, 8-14. [CrossRef]

42. Hu, W.; Du, W.; Bai, S.; Lv, S.; Chen, G. Phenoloxidase, an effective bioactivity target for botanical insecticide screening from green walnut husks. Nat. Prod. Res. 2018, 32, 2848-2851. [CrossRef] 
43. Pavela, R. Efficacy of naphthoquinones as insecticides against the house fly, Musca domestica L. Ind. Crops Prod. 2013, 43, 745-750. [CrossRef]

44. Meents, A.K.; Chen, S.-P.; Reichelt, M.; Lu, H.-H.; Bartram, S.; Yeh, K.-W.; Mithöfer, A. Volatile DMNT systemically induces jasmonate-independent direct anti-herbivore defense in leaves of sweet potato (Ipomoea batatas) plants. Sci. Rep. $2019,9,17431$. [CrossRef]

45. Kubo, I.; Uchida, M.; Klocke, J.A. An insect ecdysis inhibitor from the African medical plant Plumbago capensis (Plumbaginaceae); a naturally occurring chitin synthetase inhibitor. Agric. Biol. Chem. 1983, 47, 911-913.

46. Mitchell, M.J.; Smith, S.L. Effects of the chitin synthetase inhibitor plumbagin and its 2-dimethyl derivative juglone on insect ecdysone 20-monooxigenase activity. Experientia 1988, 44, 990-991. [CrossRef]

47. Gujar, G.T. Interaction of plumbagin with hormones in the cotton stainer, Dysdercus koenigii Fabricius. Proc. Natl. Acad. Sci. India B 1993, 9, 477-482.

48. Pradeepa, V.; Senthil-Nathan, S.; Sathish-Narayanan, S.; Selin-Rani, S.; Vasantha-Srinivasan, P.; Thanigaivel, A.; Ponsankar, A.; Edwin, E.S.; Sakthi-Bagavathy, M.; Kalaivani, K.; et al. Potential mode of action of a novel plumbagin as a mosquito repellent against the malarial vector Anopheles stephensi, (Culicidae: Diptera). Pestic. Biochem. Physiol. 2016, 134, 84-93. [CrossRef] [PubMed] 